\title{
Speech Intelligibility of Flemish Children as Judged by Their Parents
}

\author{
N.L.H. Baudonck ${ }^{a, b} \quad$ R. Buekers ${ }^{c} \quad$ S. Gillebert ${ }^{a} \quad$ K.M. Van Lierde ${ }^{a}$ \\ a Department of Otorhinolaryngology, Audiology and Speech Pathology, University of Ghent, Ghent, and \\ ${ }^{b}$ Aspirant Fonds voor Wetenschappelijk Onderzoek - Vlaanderen, Brussels, Belgium; ${ }^{C}$ Audiological Centre, \\ Hoensbroeck, The Netherlands
}

\section{Key Words}

Speech intelligibility • Child speech • Judgement of parents Normative values

\begin{abstract}
Objective: Reduced intelligibility is a central concern in speech-impaired children, especially for parents. The main purpose of this study was to develop normative data for the intelligibility of Flemish-speaking boys and girls (age 2;06$5 ; 0$ years) as judged by their parents. Additionally, the influence of familiarity, gender and age of the child was determined. Patients and Methods: Word, sentence and story productions of 163 healthy children ( 83 boys and 80 girls) between 2;06 and 5;0 years were transcribed by their own parents. Speech intelligibility was determined according to the intelligibility index described by Shriberg. Additionally, a panel of 12 unfamiliar judges listened to the recordings of a subgroup of 24 randomly selected children. Results: Speech intelligibility improved with increasing age and was around $90 \%$ for children aged $4 ; 6-5 ; 0$ years. Boys and girls performed equally on the task. For the intelligibility of words, mothers scored significantly better than unfamiliar listeners did. Conclusion: The reported normative speech intelligibility data provide important reference information for speech pathologists who assess child speech. Moreover, it enables them to measure the effect of a specific therapeutic approach and the spontaneous transfer to daily speech.
\end{abstract}

Copyright $\odot 2009$ S. Karger AG, Basel

\section{KARGER \\ Fax +4161306 1234 \\ E-Mail karger@karger.ch}

www.karger.com

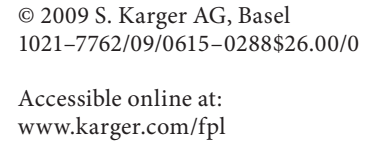

\section{Introduction}

Reduced speech intelligibility is a central concern in speech-impaired children, especially for the parents. To evaluate speech intelligibility, objective assessment procedures are needed. Speech intelligibility can be defined as ' $w$ hat is understood by the listeners of the phonetic realization of speech' [1]. De Bodt et al. [2] defined intelligibility as a product of a series of interactive processes such as phonation, articulation, resonance and prosody. Besides these basic competences of the speaker, Kent and Miolo [3] suggested that a number of other factors affect speech intelligibility, such as the nature of the spoken material, the context of communication, the listener's familiarity with the speaker, contextual support for the message to be transmitted, clarity of the visual and acoustic signals of speech, and other environmental and linguistic factors. Due to the multiple influencing variables, procedures for speech intelligibility are not widely described and they are seldom used by practicing speech-language pathologists.

For the assessment of the intelligibility of Englishspeaking children, Kent and Miolo [3] provide a clear review of the existing procedures. They classified 19 assessment procedures into 6 categories, primarily based on the linguistic level of the test material (e.g. single word, sentences, continuous speech and conversations) and manner of judgement (word identification or rating scales).

Nele Baudonck

UZ Gent 2P1, Dienst logopedie

De Pintelaan 185

BE-9000 Gent (Belgium)

Tel. +32933244 62, Fax +32933249 93, E-Mail nele.baudonck@ugent.be 
Schiavetti [4] described only two kinds of procedures to quantify the intelligibility of conversational speech, namely scaling procedures and word identification tests. In scaling procedures the listeners estimate the proportion of words correctly understood, whereas in word identification tests the listeners attempt to determine exactly what was said.

In the case of a word identification test, intelligibility can be expressed in terms of the percentage of words that are correctly understood in a speech sample, according to the 'intelligibility index' as described by Shriberg et al. [5]. This principle was used in several evaluation procedures for the assessment of intelligibility of Englishspeaking children. For example, Morris et al. [6] described the 'preschool speech intelligibility measure', based on the 'assessment of intelligibility of dysarthric speech' [7]. In this test, the 3;06- to 5-year-old children were asked to repeat 50 words, whereby each word was randomly chosen from one of the 50 lists consisting of 12 phonetically similar words. Furthermore, Gordon-Brannan and Hodson [8] obtained intelligibility measurements in the continuous speech of 48 English-speaking prekindergarten children (mean age: $4 ; 7$ years) with varying levels of phonological proficiencies and determined the percentage of words understood by unfamiliar listeners in a known context. When the percentages of the children with 'severe intelligibility involvement (i.e., least intelligible)' were excluded, the intelligibility scores ranged from 68 to $100 \%$ with a mean of $85 \%$. In a study by Chin et al. [9], 47 normal-hearing English-speaking children also reached adult-like or near-adult-like intelligibility around the age of 4 years. This seems to be consistent with the findings of previous studies by Weiss [10] and Coplan and Gleason [11].

Whereas the 'intelligibility index' described by Shriberg et al. [5] is a cross-linguistic method, the English word list proposed by Morris et al. [6] cannot be used as an evaluation procedure for the intelligibility of nonEnglish-speaking children in Flanders, the northern part of Belgium. In this region, Dutch is the majority language. The pronunciation of Standard Dutch is co-determined by the dialect surrounding the speaker. A popular term used for the variety of the Dutch language spoken in the northern part of Belgium is 'Flemish'.

Although objective and systematic procedures for measuring intelligibility are an important addition to the speech-language pathologist's testing protocol, no standardised procedures have been described to determine the percentage of speech intelligibility of Flemish-speak- ing children so far. Until now, the intelligibility of Flemish children has been assessed using scaling procedures. In addition, the speech production of Flemish children is often examined by a conventional articulation test in which Dutch speech sounds and clusters in all permissible syllable positions are elicited. Such procedures require comparison of the child's abilities with those of adults and evaluate only the sound production, and not the intelligibility as described above.

The main purpose of this study was to obtain normative data for the intelligibility of Flemish-speaking children as judged by their parents, their most important communication partners. These data can provide important reference information for speech pathologists assessing speech development and its disorders. Intelligibility judgements can be affected by multiple factors [3], specifically, the listener's familiarity with the speaker. A number of authors [12-15] have suggested that a judge who is personally familiar with the speaker may have an advantage in understanding what is being said. Moreover, several studies [16-18] found an overall superior performance of mothers over other listener groups (including the fathers). Therefore, in this study we examined the influence of the familiarity with the speaker and some other factors, such as gender (normative data for boys and girls) and age of the child. It was hypothesised that intelligibility percentages would change as a function of age and familiarity.

\section{Methods}

\section{Participants}

The parents of 181 children randomly recruited from 14 normal preschool kindergartens located in Flanders agreed to participate in the study. Before testing, the parents were asked for important information concerning the hearing, neurological, motor and physical development of the child. In addition, the spontaneous speech of each child was judged on speech, language, voice or resonance abnormalities by 2 experienced speech pathologists (N.B., S.G.). So, 18 children were excluded because of multilingualism $(\mathrm{n}=11)$, insufficient cooperation $(\mathrm{n}=4)$ and resonance or phonation disorders $(n=3)$. The remaining group of participants included 163 healthy children ranging in age from $2 ; 06$ to 5 years with a mean age of $3 ; 07$ years. There were 83 boys (mean age: $3 ; 07$ years) and 80 girls (mean age: $3 ; 07$ years). To measure the effect of age, the children were divided into five age categories, as presented in table 1 .

The parents, preferably both, acted as judges. Before participation, all parents were questioned about any hearing problems at present or in the past. Three participants with a history of hearing impairment or doubts about it were excluded. In 57 cases, 1 of the parents was unable to participate because of organizational rea- 
Table 1. Age of the 163 subjects

\begin{tabular}{|c|c|c|c|c|c|c|c|c|c|c|}
\hline & \multicolumn{2}{|c|}{$\begin{array}{l}\text { Category } 1 \\
(2 ; 06-3 ; 0 \text { years })\end{array}$} & \multicolumn{2}{|c|}{$\begin{array}{l}\text { Category } 2 \\
(3 ; 0-3 ; 06 \text { years })\end{array}$} & \multicolumn{2}{|c|}{$\begin{array}{l}\text { Category } 3 \\
(3 ; 06-4 ; 0 \text { years })\end{array}$} & \multicolumn{2}{|c|}{$\begin{array}{l}\text { Category } 4 \\
(4 ; 0-4 ; 06 \text { years })\end{array}$} & \multicolumn{2}{|c|}{$\begin{array}{l}\text { Category } 5 \\
(4 ; 06-5 ; 0 \text { years })\end{array}$} \\
\hline & girls & boys & girls & boys & girls & boys & girls & boys & girls & boys \\
\hline Number & 16 & 19 & 17 & 18 & 18 & 20 & 19 & 19 & 10 & 7 \\
\hline Total & \multicolumn{2}{|c|}{35} & \multicolumn{2}{|c|}{35} & \multicolumn{2}{|c|}{38} & \multicolumn{2}{|c|}{38} & \multicolumn{2}{|c|}{17} \\
\hline
\end{tabular}

Table 2. Mean intelligibility scores (\%) and standard deviations for each age category

\begin{tabular}{|c|c|c|c|c|c|c|c|c|c|c|}
\hline \multirow[t]{2}{*}{ Subtest } & \multicolumn{2}{|c|}{$\begin{array}{l}\text { Category } 1 \\
(2 ; 06-3 ; 0 \text { years })\end{array}$} & \multicolumn{2}{|c|}{$\begin{array}{l}\text { Category } 2 \\
(3 ; 0-3 ; 06 \text { years })\end{array}$} & \multicolumn{2}{|c|}{$\begin{array}{l}\text { Category } 3 \\
(3 ; 06-4 ; 0 \text { years })\end{array}$} & \multicolumn{2}{|c|}{$\begin{array}{l}\text { Category } 4 \\
(4 ; 0-4 ; 06 \text { years })\end{array}$} & \multicolumn{2}{|c|}{$\begin{array}{l}\text { Category } 5 \\
(4 ; 06-5 ; 0 \text { years })\end{array}$} \\
\hline & mean & SD & mean & SD & mean & $\mathrm{SD}$ & mean & $\mathrm{SD}$ & mean & $\mathrm{SD}$ \\
\hline Words & 77.88 & 12.42 & 85.81 & 9.3 & 92.18 & 9.5 & 90.31 & 8.53 & 90.78 & 7.19 \\
\hline Sentences & 45.42 & 27.80 & 62.85 & 25.64 & 77.63 & 18.76 & 80.90 & 21.51 & 90.52 & 18.82 \\
\hline Storytelling & 54.41 & 29.40 & 66.25 & 25.66 & 86.11 & 21.81 & 82.12 & 24.85 & 92.26 & 15.53 \\
\hline
\end{tabular}

$\mathrm{SD}=$ Standard deviation.

sons. In 55 cases only the mother and in 5 cases only the father listened to the recording. For the remaining 103 participants both parents actually participated.

\section{Procedure and Materials}

The Dutch intelligibility test 'Percentage Spraakverstaanbaarheid bij kinderen' (Percentage Speech Intelligibility in Children) [19] was used to measure speech intelligibility. This test consists of three subtests: naming words, producing sentences and telling a story ('Appendix A'). In the first and second subtests, 25 words and 7 sentences, respectively, were elicited by a picture-naming test. In the third subtest, the child told a short story using 4 illustrations.

The recordings and judgement sessions took place in a noiseless room at the school or at home. Two speech pathologists (N.B., S.G.) elicited the words and sentences in the children and encouraged them verbally when necessary. At the same time, they recorded the speech samples (Sony ICD-SX56 recorder) to present them to the parents afterwards in the absence of the child (laptop, Toshiba M70 with sound card and acoustic amplifier Monacor MKA-60SET/WS). The parents could listen twice to each word, sentence or story. They were asked to write down what they understood of the phonetic realisation of the child's speech. Both parents were instructed to operate completely independently. In case they had absolutely no idea about the meaning of a production, they were asked to leave the response blank. In case of doubt, they were asked to guess. Afterwards, the investigator counted the words correctly understood and determined an intelligibility percentage according to the 'intelligibility index' as described by Shriberg et al. [5]. If there was a morphological difference between the production of the child and the answer of the parents, it was handled as a correct answer because the content remained largely the same. Nonetheless, such differences were rare (less than 20 times) because most target words are uninflected.

In 24 children (12 boys and 12 girls randomly selected from each of the age categories), the parents were asked to score the same speech sample again with a time interval of 4 weeks and without reference to their first transcription. The formula 'words identically transcribed/all words transcribed' was applied, and so, a percentage of point-to-point group agreement of $88 \%$ was found.

Additionally, a panel of 12 first-year students in speech-language pathology (women ranging in age from 18 to 22 years, with a mean age of 19;03 years) who were not familiar with the speech of toddlers listened to the recordings of another subgroup of 24 randomly selected children (mean age: 3;04 years).

\section{Statistical Analysis}

SPSS for Windows (version 12.0) was used for the statistical analysis of the data. For the comparison between boys and girls and the comparisons between mothers, fathers, familiar and unfamiliar listeners, the non-parametric Mann-Whitney U test and the Wilcoxon signed ranks test were performed, respectively, with a $5 \%$ significance level. In case of multiple comparisons, Bonferroni corrections were applied. Consequently, to compare the judgements of parents and unfamiliar listeners $\alpha$ was divided by the number of comparisons $(n=6)$ and a significance criterion of 0.008 was used. 


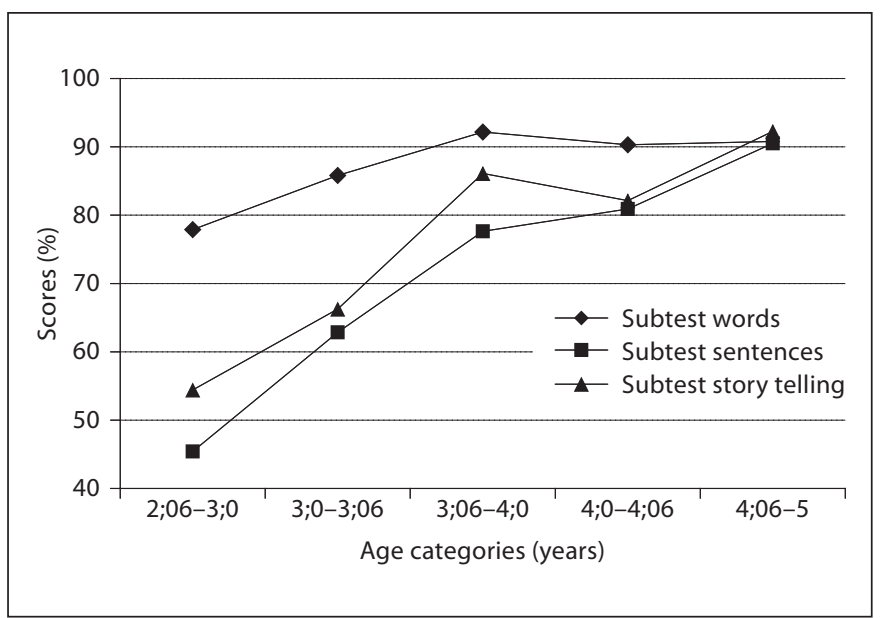

Fig. 1. Mean intelligibility scores for words, sentences and storytelling for each age category as judged by both parents.

\section{Results}

Normative data (means and standard deviations) of the intelligibility of young children as judged by their parents [19] are presented in table 2. Intelligibility for words, sentences and storytelling increased with age. Word intelligibility percentages increased from $77.88 \%$ for group 1, for mothers and fathers, to $90.78 \%$ for group 5. Sentence intelligibility increased from $45.42 \%$ for group 1 to $90.52 \%$ for group 5. Storytelling intelligibility increased from $54.41 \%$ for group 1 to $92.26 \%$ for group 5 . These developments until the fifth age category are shown in figure 1 . In table 3 , one can see that the differences of word, sentence and storytelling intelligibility scores between the three youngest age categories are significant $(\mathrm{p}<0.05)$. None of the differences between the three highest age categories are significant, except for the sentence intelligibility in age category 5 , which is significantly higher than sentence intelligibility of age category 4 .

As can be seen in table 4, there were no significant differences between boys and girls. For the subtest 'words', a significant difference $(\mathrm{p}<0.05)$ was found between the scores of mothers and fathers: maternal intelligibility scores were significantly higher than paternal intelligibility scores. On the other hand, no significant differences were observed for the subtests 'sentences' and 'storytelling' (table 5). The results of the comparison between parents' scores and scores of unfamiliar listeners are represented in table 6 . For word intelligibility, results indi-
Table 3. Comparison of the intelligibility scores of the different age categories

\begin{tabular}{llll}
\hline Subtests & Words & Sentences & $\begin{array}{l}\text { Story- } \\
\text { telling }\end{array}$ \\
\hline Category 1 vs. category 2 & $0.001^{*}$ & $0.000^{*}$ & $0.032^{*}$ \\
Category 2 vs. category 3 & $0.000^{*}$ & $0.003^{*}$ & $0.000^{*}$ \\
Category 3 vs. category 4 & 0.089 & 0.132 & 0.339 \\
Category 4 vs. category 5 & 0.996 & $0.006^{*}$ & 0.177 \\
\hline
\end{tabular}

Category $1=2 ; 06-3 ; 0$ years; category $2=3 ; 0-3 ; 06$ years; category $3=3 ; 06-4 ; 0$ years; category $4=4 ; 0-4 ; 06$ years; category $5=4 ; 06-5 ; 0$ years. Wilcoxon signed ranks test (significant at $\left.{ }^{*} \mathrm{p}<0.05\right)$.

Table 4. Comparison of intelligibility scores (\%) for boys and girls

\begin{tabular}{lllllll}
\hline Subtests & \multicolumn{2}{l}{ Mean score for } & & \multicolumn{2}{l}{ Median score for } & \multirow{2}{*}{$\mathrm{p}$} \\
\cline { 2 - 3 } & boys & girls & & boys & girls & \\
\hline Words & 87.04 & 86.43 & & 88.00 & 88.00 & 0.83 \\
Sentences & 65.51 & 71.90 & & 70.00 & 80.00 & 0.07 \\
Storytelling & 72.44 & 75.55 & & 77.00 & 88.50 & 0.31 \\
\hline
\end{tabular}

Mann-Whitney $\mathrm{U}$ test $(\mathrm{p}<0.05=$ significant $)$.

Table 5. Comparison of fathers' judgements (\%) and mothers' judgements (\%)

\begin{tabular}{lllllll}
\hline Subtests & \multicolumn{2}{l}{ Mean score for } & & \multicolumn{2}{c}{ Median score for } & $\mathrm{p}$ \\
\cline { 2 - 3 } & mothers fathers & & \multicolumn{2}{c}{ mothers fathers } & \\
\hline Words & 88.41 & 84.27 & & 92.00 & 87.00 & $0.00^{*}$ \\
Sentences & 70.74 & 65.59 & & 77.00 & 77.00 & 0.11 \\
Storytelling & 75.54 & 71.58 & & 85.00 & 85.00 & 0.11 \\
\hline
\end{tabular}

Wilcoxon signed ranks test (significant at ${ }^{*} \mathrm{p}<0.01$ ).

cated that mothers were significantly better at identifying the words than unfamiliar listeners. This trend of a maternal advantage disappeared for sentences and storytelling intelligibility. In judgments of their children's speech, fathers showed no significant difference from unfamiliar listeners. 
Table 6. Comparison of parents' judgements (\%) and unfamiliar listeners' judgements (\%)

\begin{tabular}{lllllll}
\hline & \multicolumn{1}{c}{} & & Median (1) & Median (2) & $\mathrm{p}$ \\
\hline Mother word & $(1)$ & unfamiliar word & $(2)$ & 84.00 & 72.00 & $0.00^{*}$ \\
Mother sentence & $(1)$ & unfamiliar sentence & $(2)$ & 60.00 & 53.00 & 0.24 \\
Mother story & $(1)$ & unfamiliar story & $(2)$ & 69.00 & 85.00 & 0.35 \\
Father word & $(1)$ & unfamiliar word & $(2)$ & 78.50 & 72.00 & 0.06 \\
Father sentence & $(1)$ & unfamiliar sentence & $(2)$ & 53.50 & 53.00 & 0.82 \\
Father story & $(1)$ & unfamiliar story & $(2)$ & 65.50 & 85.00 & 0.71 \\
\hline
\end{tabular}

Wilcoxon signed ranks test (significant at ${ }^{*} \mathrm{p}<0.008$ after Bonferroni correction).

\section{Discussion}

Increasing the overall speech intelligibility is the main goal of treatment in children with a speech impairment. To the best of our knowledge, research regarding the intelligibility of Flemish normal-speaking boys and girls (age 2;06-5;0 years) has not yet been reported and no standardised procedures have been described so far. Because the parents are the most important communication partners of these children, the purpose of the present study was to provide normative values for the intelligibility of words, sentences and storytelling [19] as judged by their parents.

As hypothesized, scores for intelligibility improved with increasing age of the child. After age 3;06-4;0, the intelligibility scores were not significantly related to age. This is consistent with several other studies in which normal-hearing children reached near-ceiling speech intelligibility also around the age of 4 years [8-11]. The decrease in the magnitude of differences between age categories with increasing age can be partially explained by the findings of Van den Broecke et al. [20], who found almost no errors on single phonemes from the age of 3;06 years in Flemish-speaking children.

Although language performance is generally better among girls than among boys [21, 22] and girls begin talking earlier [23] and acquire vocabulary faster [24], no significant differences could be found between the intelligibility scores for normal Flemish boys and girls in this study. To the best of our knowledge, previous studies concerning child intelligibility do not mention any differences between boys and girls either.

In our study, intelligibility scores for the children in the oldest age category reached a value around 90\% (table 2), whereas adult-like intelligibility as described in other studies [8-11] is expected to approach $100 \%$. A pos- sible explanation for this difference can be the large number of other factors affecting speech intelligibility, such as the nature of the spoken material, the context of communication, the listener's familiarity with the speaker, contextual support for the message to be transmitted, clarity of the visual and acoustic signals of speech, and other environmental and linguistic factors [3, 25-27]. The fact that in this study only audio-recorded speech samples were presented to the parents is different from daily conversations, in which conversation partners receive nonverbal information from gestures, facial expression and context. Besides, in this study an existing list of words and sentences and a fixed story were imposed on the children, whereas in spontaneous speech the children choose the context and the sentence structure themselves. So, restricted linguistic skills could have played a part in the apparent reduced maximum intelligibility score. In the youngest age categories, those restricted syntactic and morphologic skills can also account for the reduced sentence and story intelligibility in comparison with word intelligibility. As illustrated in figure 1 and table 2, the respective scores for word, sentence and story intelligibility seem to approach each other with increasing age, which can also be attributed to children's increasing syntactic and morphologic skills. Because of these inherent limitations of a structured test as suggested in this study, several studies [27-29] have argued for the use of connected speech samples for assessing intelligibility. However, conversational speech samples also have limitations, such as the lack of control and knowledge of the speech material and the time-consuming procedure. A possible correlation between the intelligibility scores obtained by our procedure and the intelligibility of spontaneous conversational speech is an interesting subject for further research. 
Furthermore, some significant differences between intelligibility scores of fathers, mothers and unfamiliar listeners were found in this study. Several previous studies demonstrated the advantage of familiar judges compared to unfamiliar listeners concerning speech intelligibility [12-15]. Our comparison between parents' scores and scores of the unfamiliar judges indicated that mothers were significantly better than fathers and unfamiliar listeners in identifying words. These findings are in agreement with the English intelligibility measures in several studies [16-18], which found that mothers were significantly better than all other listeners (including fathers) at identifying the words being spoken. This maternal advantage disappeared in the subtest sentence and storytelling. On the other hand, the significant difference between the word intelligibility scores of fathers and mothers is associated with a $4 \%$ intelligibility difference, which is well within the test-retest reliability of about $8 \%$ as reported by Yorkston and Beukelman [30] for their test. Therefore, although statistically significant, the difference between fathers and mothers in our study should be interpreted with caution. So, further research in a larger number of participants, including formal measures of contact time with the child and also educational level of the parents, may be needed to find out to what extent parents understand their child better.
In conclusion, the findings of the present study provide normative values for the words, sentences and storytelling intelligibility [19] for normal Flemish-speaking boys and girls (age: $2 ; 06-5 ; 0$ years) as judged by their parents. Kwiatkowski and Shriberg [27] found a significant difference between what the caregivers thought they understood and the amount of speech they accurately understood, as assessed by words or utterances. Decreased results of speech intelligibility compared with the available normative data can document and convince the parents of the possible presence of a speech impairment of their child. On the other hand, the reported normative speech intelligibility data provide important reference information for speech pathologists who assess articulation and articulation disorders. With these normative data the effect of a specific therapeutic approach and the spontaneous transfer to daily speech can be measured and compared. Because of the inherent limitations of the selected speech material in this study, we suggest additional measures for speech-impaired children, such as a judgement of spontaneous speech and conventional language and articulation tests to form a complete picture of the speech and language skills of the child. In addition, the test procedure proposed in this study is a convenient and non-time-consuming method which can function as an informative addition to the conventional testing protocol in Flemish-speaking children.

\section{Appendix A}

\begin{tabular}{|c|c|c|c|c|c|c|c|}
\hline \multicolumn{8}{|c|}{ Adaptation Procedure } \\
\hline \multicolumn{2}{|c|}{ Appel } & (apple) & [ apəI] & & & & \\
\hline \multicolumn{2}{|c|}{ Leeuw } & (lion) & [le:w] & & & & \\
\hline \multicolumn{2}{|c|}{ Vork } & (fork) & ['vork] & & & & \\
\hline \multicolumn{2}{|c|}{ Koffie } & (coffee) & ['kofi:] & & & & \\
\hline \multicolumn{2}{|c|}{ Sleutel } & (key) & ['sløtəl] & & & & \\
\hline \multicolumn{8}{|c|}{ Words } \\
\hline 1. & bal & (ball) & [bal] & 14. & boom & (tree) & [bo:m] \\
\hline 2. & mes & (knife) & [mes] & 15. & schoen & (shoe) & [sXun] \\
\hline 3. & aap & (monkey) & [a:p] & 16. & huis & (house) & [hœys] \\
\hline 4. & bad & (bath) & [bat] & 17. & lepel & (spoon) & ['le:pəl] \\
\hline 5. & olifant & (elephant) & ['o:lifant] & 18. & pop & (doll) & [pop] \\
\hline 6. & telefoon & (telephone) & [te:le:'fo:n] & 19. & boek & (book) & [buk] \\
\hline 7. & bed & (bed) & [bet] & 20. & bloem & (flower) & [blum] \\
\hline 8. & eten & (eating) & ['e:tən] & 21. & tafel & (table) & ['ta:fəl] \\
\hline 9. & trein & (train) & [treIn] & 22. & kat & (cat) & [kat] \\
\hline 10. & boot & (boat) & [bo:t] & 23. & slapen & (sleeping) & ['sla:pən \\
\hline 11. & banaan & (banana) & [ba'na:n] & 24. & toilet & (toilet) & [twa'let] \\
\hline 12. & muts & (cap) & [mœts] & 25. & duim & (thumb) & [dœym] \\
\hline 13. & hond & $(\mathrm{dog})$ & [hont] & & & & \\
\hline
\end{tabular}


Sentences

De hond is stout geweest. (The dog has been naughty.)

[də] ['hont] [Is] [stoyt] [gə'we:st]

De schoen zit in de tas. (The shoe is in the bag.)

[də] ['sXun] ['zIt] [In] [də] [tas]

Het paard gaat eten. (The horse is going to eat.)

[hət] [pa:rt] [ga:t] ['e:tən]

Deze meneer heeft een baard, die meneer heeft geen baard. (This man has a beard, this man has no beard.)

['de:zə] [mə'ne:r] [he:ft] [ən] [ba:rt], [di] [mə'ne:r] [he:ft] [ge:n] [ba:rt]

Het kind zingt een liedje aan de telefoon. (The child sings a song on the telephone.)

[hət] ['kInt] [zInt] [ən] ['li:cə] [a:n] [də] [te:le:'fo:n]

Op mijn pyjama staan mooie bloemen. (There are beautiful flowers on my pyjama.)

[op] [meIn] [pi:'ja:ma] [sta:n] ['mo:jə] ['blumən]

Met die sleutel kan je de koffer openmaken. (With this key you can open the box.)

[met] ['dezə] ['sløtəl] [kan] [jə] [də] ['kofər] ['o:pən'ma:kən]

\section{Storytelling}

'The story of the monkey who received a banana from a man.'

Example of a possible story according to the pictures presented:

De man (meneer) geeft een banaan aan de aap. (The man gives a banana to the monkey.)

[də] [man] [ge:ft] [ən] [bana:n] [a:n] [də] [a:p]

De aap eet de banaan op. (The monkey eats the banana.)

[də] [a:p] [e:t] [də] [bana:n] [op]

De aap gooit de schil weg. (The monkey throws the peel away.)

[də] [a:p] [go:jt] [də] [sXil] [weX]

De man glijdt uit/valt over de schil. (The man slips over the skin.)

[də] [man] [gleIt] [o:vər] [də] [sXIl]

\section{References}

-1 Yorkston KM, Strand EA, Kennedy MRT: Comprehensibility of dysarthric speech implications for assessment and treatment planning. Am J Speech Lang Pathol 1996;5: 55-66.

$\checkmark 2$ De Bodt MS, Hernandez-Diaz HM, Van De Heyning PH: Intelligibility as a linear combination of dimensions in dysarthric speech. J Commun Disord 2002;35:283-292.

3 Kent DR, Miolo G: The intelligibility of children's speech. Am J Speech Lang Pathol 1994;3:81-95.

4 Schiavetti N: Scaling procedures for the measurement of speech intelligibility; in Kent RD (ed): Intelligibility in Speech Disorders: Theory, Measurement and Management. Amsterdam, Benjamins, 1992, pp 1134.

-5 Shriberg LD, Austin D, Lewis BA, McSweeny JL, Wilson DL: The percentage of consonants correct (PCC) metric: extensions and reliability data. J Speech Lang Hear Res 1997; 40:708-722.

6 Morris SR, Wilcox AK, Schooling TL: The preschool speech intelligibility measure. Am J Speech Lang Pathol 1995;4:22-28.
7 Yorkston KM, Beukelman DR: Ataxic dysarthria: treatment sequences based on in telligibility and prosodic considerations. J Speech Hear Disord 1981;46:398-404.

8 Gordon-Brannan MHW, Hodson BW: Intelligibility/severity measurements of prekindergarten children's speech. Am J Speech Lang Pathol 2000;9:141-150.

$\checkmark$ Chin SB, Tsai PL, Gao S: Connected speech intelligibility of children with cochlear implants and children with normal hearing. Am J Speech Lang Pathol 2003;12:440-451.

10 Weiss CE: Weiss Intelligibility Test. Tigard, CC Publications, 1982.

11 Coplan J, Gleason JR: Unclear speech: recognition and significance of unintelligible speech in preschool children. Pediatrics 1988;82:447-452.

12 Beukelman DR, Yorkston KM: Influence of passage familiarity on intelligibility estimates of dysarthric speech. J Commun Disord 1980;13:33-41.

13 Boothroyd A: Evaluation of speech production of the hearing impaired: some benefits of forced-choice testing. J Speech Lang Hear Res 1985;28:185-196.
14 McGarr N: The intelligibility of deaf speech to experienced and inexperienced listeners. J Speech Hear Res 1983;26:451-458.

15 Monsen RB: A usable test for the speech intelligibility of deaf talkers. Am Ann Deaf 1981;126:845-852.

16 Weist RM, Kruppe B: Parent and sibling comprehension of children's speech. J Psycholinguist Res 1977;6:49-58.

17 Goehl H, Martin P: Intelligibility and familiarity: is experience enough? American Speech-Language-Hearing Association Convention, New Orleans, 1987.

18 Flipsen P Jr: Speaker-listener familiarity: parents as judges of delayed speech intelligibility. J Commun Disord 1995;28:3-19.

19 Buekers R, Dekelver J, Zoons M: Beoordeling en Meting Percentage Spraakverstaanbaarheid bij Kinderen. Logopedie 2005;17:2332.

20 Van den Broecke M, Ruijters S, Van der Meulen S: Verschillen in moeilijkheidsgraad in distinctieve kenmerken bij consonanten en consonant clusters. Logopedie Foniatrie 1984;56:2-9. 
-21 Bornstein MH, Haynes OM, Painter KM, Genevro JL: Child language with mother and with stranger at home and in the laboratory: a methodological study. J Child Lang 2000; 27:407-420.

-22 Dionne G, Dale PS, Boivin M, Plomin R: Genetic evidence for bidirectional effects of early lexical and grammatical development. Child Dev 2003;74:394-412.

23 Murray AD, Johnson J, Peters J: Fine-tuning of utterance length to preverbal infants: effects on later language development. J Child Lang 1990;17:511-525.
24 Roulstone S, Loader S, Beveridge M, Northstone K: The speech and language of children aged 25 months: descriptive data from the Avon Longitudinal Study of Parents and Children. Early Child Dev Care 2002;172: 259-268.

25 Black JW: Multiple choice intelligibility test. J Speech Hear Disord 1957;22:213-235.

$>26$ Hood JD, Poole JP: Influence of the speaker and other factors affecting speech intelligibility. Audiology 1980;19:434-455.

-27 Kwiatkowski J, Shriberg LD: Intelligibility assessment in developmental phonological disorders: accuracy of caregiver gloss. J Speech Hear Res 1992;35:1095-1104.
28 Morrison JA, Shriberg LD: Articulation testing versus conversational speech sampling. J Speech Hear Res 1992;35:259-273.

29 Weston AD, Shriberg LD: Contextual and linguistic correlates of intelligibility in children with developmental phonological disorders. J Speech Hear Res 1992;35:13161332.

30 Yorkston KM, Beukelman DR: Assessment of Intelligibility of Dysarthric Speech. Austin, Pro-Ed, 1981. 